\title{
Reduced intracellular magnesium concentrations in asthmatic patients
}

\author{
A. Emelyanov*, G. Fedoseev*, P.J. Barnes**
}

\begin{abstract}
Reduced intracellular magnesium concentrations in asthmatic patients. A. Emelyanov, G. Fedoseev, P.J. Barnes. C) ERS Journals Ltd 1999.

ABSTRACT: Magnesium is important in the regulation of bronchomotor tone, and low dietary intake of magnesium has been associated with airway hyperresponsiveness in epidemiological studies.

The concentration of magnesium in serum, erythrocytes and urine in 49 patients with asthma (29 males, aged 15-65 yrs) and in 25 normal subjects (15 males, aged 17 36 yrs) was studied by atomic absorption.

Magnesium concentrations were significantly lower in erythrocytes and urine in both atopic $(n=26)$ and nonatopic $(n=23)$ asthmatic patients as compared with the control group, whereas serum concentrations did not differ. The concentration of magnesium in erythrocytes was not related to the degree of airway obstruction as measured by forced expiratory volume in one second (FEV1) but was significantly correlated with airway hyperresponsiveness measured as the provocative concentration causing a $20 \%$ fall in FEV1 to inhaled acetylcholine $(r=0.64 ; p<0.05)$. In addition, a magnesium tolerance test showed increased retention of magnesium $(58.9 \%$ of administered dose in asthmatic patients compared with $8.9 \%$ in normal subjects, p<0.05).

In conclusion, the low cellular concentration of magnesium may be associated with airway hyperresponsiveness in asthmatic patients.
\end{abstract}

Eur Respir J 1999; 13: 38-40. \author{
UK. \\ Correspondence: A. Emelyanov \\ Hospital Therapeutic Clinic \\ Pavlov's Medical University \\ 6/8 L. Tolstogo Str \\ St Petersburg 197089 \\ Russia \\ Fax: 0078122342749
}

*Hospital Therapeutic Clinic, Pavlov's Medical University, St Petersburg, Russia. **Dept of Thoracic Medicine, National Heart and Lung Institute, London,

Keywords: Airway hyperresponsiveness asthma

magnesium

Received: January 301998

Accepted after revision September 31998
Magnesium is involved in the regulation of bronchial tone, mast cell secretion and neuromuscular conductivity [1]. A high dietary magnesium intake is associated with better lung function, and a reduced risk of airway hyperreactivity and wheezing in a general population [2]. Magnesium sulphate gives a dose-dependent bronchodilator effect and decreases airway hyperresponsiveness to methacholine and histamine in asthmatic patients [3-7], although not all studies have confirmed this [8-11]. In a single case report hypomagnesemia appeared to induce air-way hyperresponsiveness to histamine and was reversed after magnesium infusion [12]. Dietary supplementation with magnesium resulted in improvement of symptoms in asthmatic patients [13]. Magnesium levels, therefore, may have clinical importance in asthma.

The aim of the present study was to investigate the concentrations of magnesium in serum, erythrocytes and daily urine and its relationship with airway obstruction and airway hyperresponsiveness in patients with asthma.

\section{Methods}

\section{Patients}

Twenty-six patients (15 males, 11 females) with atopic bronchial asthma, 23 nonatopic asthmatic patients (14 males, 9 females) in clinical remission (aged 15-65 yrs, median age 36 yrs) were examined at the Hospital Therapeutic Clinic of Pavlov's Medical University, St Petersburg, Russia. Laboratory tests were performed at the Department of Thoracic Medicine, National Heart and Lung Institute, London, UK. Patients were diagnosed according to the American Thoracic Society definition of asthma [14]. Diagnosis was based upon clinical history, reversibility of forced expiratory volume in one second $(\mathrm{FEV} 1)>15 \%$ and diurnal variability of peak expiratory flow rate $>20 \%$. Their mean duration of asthma was $10.3 \pm 1.0$ yrs (mean \pm SEM), and their mean FEV1 at the time of the study was $81.9 \% \pm 3.7 \%$ predicted (mean \pm SEM). Thirty-five patients were nonsmokers and 14 were exsmokers. Patients stopped receiving medications $\left(\beta_{2}\right.$-agonists, disodium cromoglycate, inhaled steroids, theophylline) at least $72 \mathrm{~h}$ before the measurement. None had never received systemic steroids within 3 month of the treatment.

Twenty-five healthy nonasthmatic nonsmoking subjects (15 males, 10 females) aged 17-36 yrs (median age 30 yrs) from the same population served as a control group. They were chosen according to the following criteria: 1) negative allergic, pulmonary, digestive and occupation history; 2) normal airway conductance; and 3) negative acetylcholine challenge test.

The study was approved by the Local Ethics Committee. The participants were informed in writing and their consent was obtained orally.

\section{Lung function tests}

Pulmonary function tests included airway resistance, specific airway conductance (Respiratory system 3000; Ohio Medical Products, Madison, OH, USA), forced vital capacity, FEV1, mid-expiratory flow at 25,50 and $75 \%$ of vital capacity (Pneumoscreen II; Jaeger, Hoechberg, Germany). Acetylcholine challenge test was performed according to the method described by OREHEK et al. [15], with the provocative concentration causing a $20 \%$ fall in FEV1 (PC20) as a measure of airway responsiveness. 


\section{Magnesium concentration}

The concentrations of magnesium in serum, erythrocytes and $24 \mathrm{~h}$ urine were measured by atomic absorption spectrometry (Model 508; Hitachi, Tokyo, Japan) in duplicate.

Erythrocytes were separated from $20 \mathrm{~mL}$ heparinized blood. This amount was sufficient for the examination of patients and the relation between erythrocyte magnesium, airway obstruction and hyperresponsiveness. Samples were taken at 09:00-10:00 h after overnight fast. After centrifugation erythrocytes were washed twice with isotonic $\left(290 \mathrm{mosmol} \cdot \mathrm{L}^{-1}\right)$ lithium chloride solution $\left(145 \mathrm{mmol} \cdot \mathrm{L}^{-1}\right)$. Erythrocytes were counted in a celloscope and then lysed by the addition of deionized water. Proteins were precipitated by $6 \%$ trichloracetic acid. The lysate was frozen and stored at $-20^{\circ} \mathrm{C}$ until assay.

A magnesium tolerance test was performed in 16 asthmatic patients and six normal subjects according to the method described by RYzen et al. [16]. After baseline $24 \mathrm{~h}$ urine collection patients were given $0.2 \mathrm{mEq} \cdot \mathrm{kg}$ lean body weight $^{-1}$ of intravenous magnesium in $50 \mathrm{~mL}$ of $0.9 \%$ sodium chloride during $4 \mathrm{~h}$. Twenty-four hour urine samples beginning with the infusion were again collected for determination of urine magnesium excretion. Percentage magnesium retained was calculated.

\section{Statistics}

Student's unpaired two-tailed t-test, ANOVA (Fisher's test) and correlation coefficient (r) were used for statistical methods (Microsoft Excel 5; Redwood, WA, USA and Statistica for Windows 5; Stat Soft, Tulsa, OK, USA). Calculations were made with $95 \%$ confidence intervals (CI) and a p-value $<0.05$ was considered significant.

\section{Results}

The concentrations of magnesium in blood and daily urine in different groups are shown in table 1. The difference between the concentration of plasma creatinine in asthmatic patients $\left(0.09 \mathrm{mmol} \cdot \mathrm{L}^{-1}\right)$ and healthy subjects $\left(0.10 \mathrm{mmol} \cdot \mathrm{L}^{-1}\right)$ was not significant $(\mathrm{p}>0.05)$. The concentrations of magnesium in serum in asthmatic patients did not differ from those in healthy subjects. The concentrations of magnesium in erythrocytes and daily urine in both groups of asthmatic patients were significantly lower than in the control group. The mean of retention of magnesium during parenteral magnesium tolerance test was $58.9 \pm$ $5.0 \%$ (mean $\pm \mathrm{SEM})$ of administrated dose in asthmatic subjects $(95 \%$ CI $47.9-69.5)$ and $8.9 \pm 3.3 \%$ in the control group $(95 \%$ CI $0.3-17.4 ; \mathrm{p}<0.05)$.

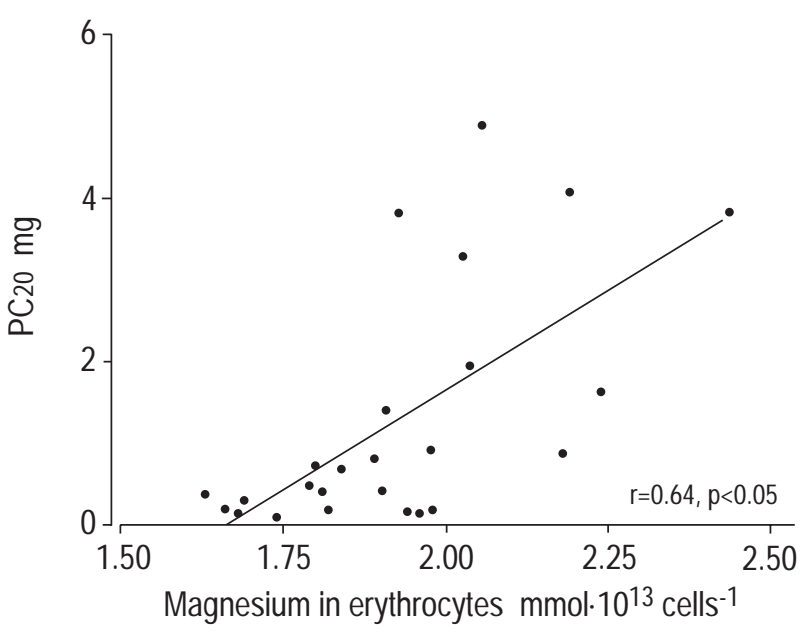

Fig. 1. - Correlation between concentration of magnesium in erythrocytes and airway hyperresponsiveness to acetylcholine (provocative concentration causing a $20 \%$ fall in forced expiratory volume in one second $(\mathrm{PC} 20))$ in asthmatic patients.

The concentrations of magnesium in erythrocytes and urine were not related $(\mathrm{r}=0.01$ and $-0.10, \mathrm{n}=43$ respectively, $p>0.05$ ) to the severity of airways obstruction, as measured by per cent predicted FEV1. However, there was a significant correlation between the concentration of magnesium in red cells and $\mathrm{PC} 20$ to acetylcholine $(\mathrm{r}=0.64$; $\mathrm{n}=25, \mathrm{p}<0.05$ ) (fig. 1).

\section{Discussion}

The concentration of magnesium in the serum of asthmatic patients did not differ significantly from that found in healthy subjects. However, magnesium is an intracellular ion and the correlation between its level in serum and cells is poor [17]. In contrast, a low magnesium concentration in erythrocytes and daily urine was found in asthmatic patients compared to the normal subjects. A parenteral magnesium tolerance test showed significantly higher retention of magnesium in patients with asthma compared with control subjects. This may reflect a relative magnesium deficiency in several cell types, including inflammatory cells, smooth and skeletal muscles. These data are in agreement with a previous report of low concentrations of magnesium in skeletal muscles and polymorphonuclear leukocytes in asthmatic patients $[18,19]$.

To assess the clinical relevance of magnesium deficiency, the relationship between the concentration of magnesium in erythrocytes, FEV1 and airway hyperresponsiveness

Table 1. - Concentrations of magnesium in serum, erythrocytes and urine in asthmatic patients and normal subjects

\begin{tabular}{|c|c|c|c|c|c|}
\hline & $\begin{array}{l}\text { Normal subjects } \\
\qquad(\mathrm{n}=25)\end{array}$ & $\begin{array}{l}\text { Atopic asthmatics } \\
\qquad(\mathrm{n}=26)\end{array}$ & $\begin{array}{l}\text { Non-atopic asthmatics } \\
\qquad(\mathrm{n}=23)\end{array}$ & F-value & p-value \\
\hline Serum $\mathrm{mmol} \cdot \mathrm{L}^{-1}$ & $\begin{array}{l}0.83 \pm 0.024 \\
(0.78-0.88)\end{array}$ & $\begin{array}{l}0.84 \pm 0.025 \\
(0.79-0.89)\end{array}$ & $\begin{array}{l}0.87 \pm 0.030 \\
(0.82-0.93)\end{array}$ & 1.04 & $>0.05$ \\
\hline Erythrocytes $\mathrm{mmol} \cdot 10^{13}$ cells $^{-1}$ & $\begin{array}{l}2.19 \pm 0.047 \\
(2.09-2.28)\end{array}$ & $\begin{array}{c}1.91 \pm 0.059 * * \\
(1.78-2.03)\end{array}$ & $\begin{array}{c}1.90 \pm 0.068 * * \\
(1.7-2.04)\end{array}$ & 8.72 & $<0.001$ \\
\hline Urine $\mathrm{mmol} \cdot 24 \mathrm{~h}^{-1}$ & $\begin{array}{c}6.13 \pm 1.06 \\
(3.69-8.58)\end{array}$ & $\begin{array}{c}3.69 \pm 0.26 \\
(3.16-4.22)\end{array}$ & $\begin{array}{l}3.71 \pm 0.33 * \\
(3.02-4.39)\end{array}$ & 6.73 & $<0.003$ \\
\hline
\end{tabular}

Values are presented as mean \pm SEM with $95 \%$ confidence intervals in parenthesis. F-value: Fisher's test. *: $\mathrm{p}<0.05 ; * *$ : $\mathrm{p}<0.001$ for asthmatic versus normal subjects. 
to acetylcholine were determined. Although no correlation between the concentration of magnesium in red blood cells and FEV1 was found, the concentration of magnesium in erythrocytes was significantly correlated with the PC20 to acetylcholine. It is possible to speculate that a low intracellular magnesium concentration may promote airway hyperresponsiveness in asthmatic patients. This observation may explain why the administration of magnesium and a higher magnesium intake reduced airway hyperresponsiveness [2, 6, 7].

Magnesium deficiency is known to increase intracellular concentrations of calcium, the degree of lipid peroxidation and secretion of histamine and inflammatory cytokines (interleukin (IL)-1, IL-6) [20, 21]. Magnesium also inhibits cholinergic transmission [22]. This may explain why an intracellular magnesium deficiency may be associated with airway inflammation and airway hyperreactivity in asthmatic patients. The findings of the present study are in contrast with the data of DE VALK et al. [23] who reported similar magnesium concentration in blood cells of asthmatic patients and control subjects. However, this may reflect the differences in magnesium intake between different countries.

The cause of magnesium deficiency in asthmatic patients is unknown. It is unlikely to result from the usage of antiasthma medications ( $\beta_{2}$-agonists, theophylline and inhaled steroids) as the patients in the present study stopped receiving all drugs for at least $72 \mathrm{~h}$ before the study. The low magnesium concentration was found in both allergic and nonallergic patients, so it cannot be due to atopy. It is possible that the magnesium deficiency may result from a low magnesium intake. Magnesium is obtained principally from cereals, nuts, green vegetables and dairy produce. However, it is lost in the cooking or refining of food, so diets that provide a high proportion of daily calorie requirements from refined or processing foods are likely to be low in magnesium. Low magnesium intake may be involved in the aetiology of asthma [2]. Magnesium deficiency resulting in airway hyperresponsiveness has been reported to be reversed after administration of magnesium in a single case report [13]. On the other hand, the low concentration of magnesium may be genetically determined [24]. Further investigation is needed to assess the factors that underlie magnesium deficiency in asthmatic patients.

In conclusion, this study has revealed magnesium deficiency in erythrocytes and its relation with airway hyperresponsiveness in asthmatic patients. These findings provide evidence that low intracellular magnesium concentration may be associated with airway hyperresponsiveness in patients with asthma. Further studies are needed to determine whether long-term magnesium supplements and a higher dietary magnesium intake have a favourable effect in asthma.

\section{References}

1. Mathew R, Altura BM. The role of magnesium in lung diseases: asthma, allergy and pulmonary hypertension. Magnes Trace Element 1992; 10: 220-228.

2. Britton J, Pavord I, Richards K, et al. Dietary magnesium, lung function, wheezing, and airway hyperreactivity in a random adult population samples. Lancet 1994; 344: $357-362$.

3. Okayama H, Aikawa T, Okayama M, Sasaki H, Mue S, Takishimi T. Bronchodilating effect of intravenous magnesium sulphate in bronchial asthma. JAMA 1987; 257: 1076-1078.
4. Noopen M, Vanmaele L, Impence N, Schandevyl W. Bronchodilating effect of intravenous magnesium sulphate in acute severe bronchial asthma. Chest 1990; 97: 373-376.

5. Bloch H, Silverman R, Mancherje N, Grant S, Jagminas $\mathrm{L}$, Scharf SM. Intravenous magnesium sulphate as an adjunct in the treatment of acute asthma. Chest 1995; 107: 1576-1581.

6. Rola G, Bucca C, Bugiani M, Arrosa W, Spinaci S. Reduction of histamine-induced bronchoconstriction by magnesium in asthmatic subjects. Allergy 1987; 42: 186-188.

7. Rola G, Bucca C, Arrosa W, Bugiani M. Magnesium attenuates metacholine-induced bronchial constriction in asthmatics. Magnesium 1987; 6: 201-204.

8. Bernstein WK, Khastgir T, Khastgir A, et al. Lack of effectiveness of magnesium in chronic stable asthma. Arch Intern Med 1995; 155: 271-276.

9. Tiffany BR, Berk WA, Todd IK, White SR. Magnesium bolus or infusion fails to improve expiratory flow in acute asthma exacerbations. Chest 1993; 104: 831-834.

10. Matusiewicz S, Cusack S, Greening AP, Crompton GK. A double-blind, placebo-controlled, parallel group study of intravenous magnesium sulphate in acute severe asthma (Abstract). Eur Respir J 1994; 7: Suppl. 18, 14s.

11. Chande VT, Skoner DP. A trial of nebulised magnesium sulphate to reverse bronchospasm in asthmatic patients. Ann Emerg Med 1992; 21: 1111-1115.

12. Rolla G, Bucca C. Hypomagnesemia and bronchial hyperreactivity: a case report. Allergy 1989; 44: 519-521.

13. Hill J, Micklewright A, Lewis S, Britton J. Investigation of the effect of short-term change in dietary magnesium intake in asthma. Eur Respir J 1997; 10: 2225-2229.

14. American Thoracic Society. Standards for the diagnosis and care of patients with chronic obstructive pulmonary disease (COPD) and asthma. Am Rev Respir Dis 1987; 136: 225-244.

15. Orehek J, Gayrard P, Smith AP, Grimaud C, Charpin J. Airway response to carbachol in normal and asthmatic subjects. Am Rev Respir Dis 1977; 115: 937-943.

16. Ryzen E, Elbaum N, Singer FR, Rude RK. Parenteral magnesium tolerance testing in the evaluation of magnesium deficiency. Magnesium 1985; 4: 137-147.

17. Ralston MA, Murnane MR, Kelley RE, Altshuld RA, Unveferth DV, Leier CV. Magnesium content of serum, circulating mononuclear cells, skeletal muscles and myocardium in congestive heart failure. Circulation 1989; 80: 573-580.

18. Gustafson T, Boman K, Rosenhall L, Sandstrom T, Wester PO. Skeletal muscle magnesium and potassium in asthmatics treated with oral $\beta_{2}$-agonists. Eur Respir J 1996; 9: 237-240.

19. Fantidis P, Ruiz Cacho J, Marin M, Madero Jarabo R, Solera J, Herrero E. Intracellular (polymorphonuclear) magnesium content in patients with bronchial asthma between attacks. J Roy Soc Med 1995; 88: 441-445.

20. Weglicki WB, Phillips TM. Pathobiology of magnesium deficiency: a cytokine/neurogenic inflammation hypothesis. Am J Physiol 1992; 263: 734-737.

21. Zhang A, Cheng TPA, Altura BM. Magnesium regulates intracellular free ionized calcium concentration and cells geometry in vascular smooth muscle cells. Biochem Biophys Acta 1992; 1134: 25-29.

22. Del Castillo J, Engback L. The mechanism of neuromuscular block produced by magnesium. J Physiol 1954; 124: $370-384$.

23. de Valk HM, Kok PTM, Struyvenberg A, et al. Extracellular and intracellular magnesium concentrations in asthmatic patients. Eur Respir J 1993; 6: 1122-1125.

24. Henrotte JG, Pla M, Dausset J. HLA and $\mathrm{H}_{2}$-associated variation of intra - and extracellular magnesium contents. Proc Natl Acad Sci USA 1990; 87: 1894-1898. 